\title{
PARTISIPASI MASYARAKAT DAN MUTU PENDIDIKAN DI KABUPATEN BOJONEGORO
}

\author{
Sri Minarti ${ }^{1}$ \\ Institut Agama Islam (IAI) Sunan Giri Bojonegoro \\ Email: sri.arti10@gmail.com
}

\begin{abstract}
"The quality of education is the top priority of every education unit in Bojonegoro Regency so that various activities programs are raised by schools and establish cooperation with communities especially parents of student guardians or committees in the form of active participation and involvement in various fields. This study included the qualitative type of data collection with observation, documents, and authority, analyzed by qualitative descriptive to answer the research focus on the form of committee participation and the quality of education in SMP N 1 and SMP N 2 Bojonegoro. The results of the study indicate that committee participation in educational units in the academic and non-academic fields, for example, input curriculum development, infrastructure or funding. The quality of education in two schools can be proven by the fulfillment of eight educational standards and added one character standard which is input from the committee as well as high public interest in the school, and alumni accepted in favorite secondary schools (input, process, and output). The answer to the two research focuses is in accordance with Johnlitlle's theory of participation and Deming's theory of quality."
\end{abstract}

Keywords: Community Participation and Quality of Education

\section{Pendahuluan}

Kualitas pendidikan menjadi problem besar bangsa Indonesia, berbagai usaha dan upaya dilakukan untuk mencari jalan keluarnya, seperti dengan pengembangan kurikulum Nasional, peningkatan kompetensi guru dan kepala sekolah melalui pelatihan, pengadaan buku dan sarana prasarana pembelajaran, perbaikan manajemen sekolah, serta memaksimalkan peran masyarakat dalam hal ini komite dan wali murid ${ }^{2}$, namun demikian sampai saat ini hasilnya belum maksimal. Beberapa faktor penting dalam implementasi peningkatan kualitas pendidikan dan perlu diperhatikan adalah sistem pendidikan dan adanya partisipasi masyarakat yang tinggi.

Menurut UU Sistem Pendidikan Nasional No. 20 tahun $2003^{3}$, partisipasi masyarakat dapat tergabung dalam organisasi dewan pendidikan, komite sekolah/madrasah dan kelompok masyarakat itu sendiri. Partisipasi masyarakat menjadi faktor penting dalam peningkatan kualitas pendidikan, maka diperlukan bentuk program kegiatan partisipasi masyarakat yang jelas. Sumber daya manusia dari orang tua siswa yang mumpuni menjadi penentu dalam menjalankan pendidikan di era global, dan merupakan

\footnotetext{
${ }^{1}$ Dosen tetap pada prodi PAI Fakultas Tarbiyah IAI Sunan Giri Bojonegoro

${ }^{2}$ Hasil obsevasi Dewan Pendidikan di SD, MI, SMP, MTs di Kabupaten Bojonegoro tahun 2018.

${ }^{3}$ Undang Undang RI. No: 20 Tahun 2003. Tentang Sistim Pendidikan Nasional. Depdiknas. Jakarta: hlm. 25
} 


\section{Sri Minarti}

modal dasar yang keberadaannya sangat dibutuhkan oleh lembaga pendidikan. Kualitas manusia yang baik akan mampu mewujudkan pendidikan yang baik pula, dan akan tercermin dalam bentuk partisipasi pada pendidikan dimana anak-anak mereka disekolahkan. Pendidikan dikatakan baik dan berkualitas apabila dalam input, proses, output, dan outcome mampu menjawab tuntutan perubahan zaman dan mempelopori terjadinya perubahan.

Berdasarkan hasil penelitian, bahwa untuk meningkatkan kualitas pendidikan dapat melalui dua jalur, pertama membangun sistem pendidikan dan kedua memaksimalkan partisipasi masyarakat. Sekolah Negeri seharusnya dapat ditingkatkan kualitasnya melalui fungsi dan peran aktif masyarakat dalam bingkai komite dan wali murid sekolah tersebut secara maksimal. Berbagai program kegiatan dilakukan oleh SMP Negeri 1 dan SMP Negeri 2 Bojonegoro sebagai upaya meningkatkan kualitas pendidikan, memaksimalkan peran komite dan paguyuban wali murid dalam pelaksanaannya. Penelitian ini akan mengkaji tentang bentuk-bentuk partisipasi masyarakat (komite dan wali murid) yang dapat meningkatkan kualitas atau mutu pendidikan di SMPN 1 dan SMPN 2 Bojonegoro. SMPN 1 dan SMPN 2 Bojonegoro termasuk kategori sekolah menengah pertama dan telah banyak prestasi serta mendapat kepercayaan masyarakat, terbukti dengan banyaknya jumlah pendaftar untuk diterima sebagai peserta didik dan berbagai penghargaan.

\section{Masalah Penelitian}

1. Bagaimana program kegiatan partisipasi masyarakat (komite dan paguyuban wali murid) dalam meningkatkan kualitas pendidikan di SMPN 1 dan SMPN 2 Bojonegoro?

2. Bagaimana Kualitas pendidikan (input proses dan out-put) di SMPN 1 dan SMPN 2 Bojonegoro?

\section{Pembatasan Masalah}

Menurut Undang-undang Republik Indonesia Nomor 20 Tahun 2003 tentang Sistem Pendidikan Nasional ${ }^{4}$ pada pasal 36 ayat 3 ditegaskan bahwa "Komite sekolah, sebagai lembaga mandiri, dibentuk dan berperan dalam peningkatan mutu pelayanan dengan memberikan pertimbangan, arahan dan dukungan tenaga, sarana dan prasarana, serta pengawasan pendidikan pada tingkat sekolah. Jadi partisipasi masyarakat dimaksudkan dalam penelitian ini merupakan program kegiatan komite sekolah dan paguyuban kelas di SMPN 1 dan SMPN 2 Bojonegoro, meliputi pembiayaan, masukan/saran, dan pengawasan. Adapun peningkatan kualitas pendidikan meliputi input (masukan), proses dan output (lulusan). Peningkatan kualitas sumber daya manusia diantaranya meliputi; peningkatan kualitas kepala sekolah, pendidik, tenaga kependidikan, peserta didik dengan berbagai kegiatan. Peningkatan sarana prasarana misalnya pengadaan bangunan gedung dan perlengkapan sekolah, memberi masukan terkait kurikulum, visi, misi tujuan dan sasaran sekolah. Dalam upaya

\footnotetext{
${ }^{4}$ Undang Undang RI. No: 20 Tahun 2003. Tentang ... hlm. 24
} 


\section{PARTISIPASI MASYARAKAT DAN MUTU PENDIDIKAN}

peningkatan kualitas proses dalam pembelajaran meliputi ikut serta dalam pembuatan keputusan, proses pengelolaan lembaga, proses monitoring dan evaluasi. Sedangkan untuk mengukur mutu atau kualitas output, sebagai parameternya adalah adanya lulusan yang berprestasi di bidang akademis dan nonakademis.

Lokasi penelitian di SMPN 1 dan SMPN 2 Bojonegoro, terkenal di kalangan masyarakat Bojonegoro sebagai sekolah yang sudah maju atau berkualitas serta partisipasi masyarakat (komite dan wali murid) sangat tinggi, dan SMPN 1 SMPN 2 Bojonegoro di bawah naungan Dinas Pendidikan Kabupaten Bojonegoro. Waktu penelitian selama enam bulan, dari Juli - Desember 2018

\section{Signifikansi Penelitian}

1. Pengembangan teori sosial yaitu partisipasi masyarakat dalam meningkatkan mutu pendidikan. Bahwa partisipasi masyarakat sebagai salah satu penentu dalam meningkatkan kualitas pendidikan.

2. Bermanfaat memperkaya teori partisipasi masyarakat dalam meningkatkan mutu pendidikan di sekolah negeri pada jenjang pendidikan sekolah pertama negeri.

3. Memperkaya teori mutu pendidikan di Sekolah yang meliputi input, proses dan output.

\section{Signifikansi Praktis}

1. Bagi para kepala sekolah, pemimpin pada umumnya dapat mengembangkan berbagai macam bentuk partisipasi komite dan paguyuban atau wali murid guna meningkatkan kualitas pendidikan.

2. Bagi pemimpin pendidikan, kajian ini diharapkan memberikan konstribusi berupa penerapan bentuk partisipasi masyarakat (komite dan wali murid) dalam meningkatkan kualitas pendidikan.

3. Sebagai bahan pertimbangan Dinas Pendidikan di Indonesia dalam menumbuh kembangkan kualitas pendidikan di Sekolah Menengah Pertama Negeri dengan pendekatan partisipasi masyarakat.

4. Bagi SMPN 1 dan SMPN 2 Bojonegoro, dengan adanya partisipasi masyarakat akan lebih meningkatkan kualitas pendidikannya.

5. Bagi peneliti lebih lanjut, agar dapat mengembangkan penelitiannya tentang bentuk-partisipasi masyarakat lebih banyak lagi guna meningkatkan kualitas pendidikan pada satuan pendidikan yang berbeda.

\section{Kajian Pustaka/Riset Sebelumnya}

Dibentuknya komite sekolah dimaksudkan sebagai wadah pemberdayaan peran serta masyarakat. Komite merupakan mitra sekolah dalam upaya membangun komitmen dan loyalitas serta kepedulian masyarakat terhadap peningkatan kualitas sekolah. Adapun tujuan dibentuknya komite sekolah adalah organisasi masyarakat di sekolah sebagai berikut: Mewakili dan menyalurkan ide gagasan masyarakat dalam merumuskan kebijakan program pendidikan di satuan pendidikan, dan meningkatkan peran serta tanggung jawab masyarakat dalam penyelenggaraan pendidikan di satuan 


\section{Sri Minarti}

pendidikan. Menciptakan kondisi dan suasana yang demokratis serta dapat dipertanggung jawabkan dan peningkatan pelayanan pendidikan berkualitas.

Keberadaan komite sekolah bertumpu pada Permendikbud No. 75 Tahun 2016 yang pada intinya sebagai bentuk peran partisipasi masyarakat dalam meningkatkan kualitas satuan pendidikan di sekolah. Pembentukkan komite sekolah telah diatur dalam permen tersebut, termasuk peran, fungsi dan pertatanggung jawabannya. Adapun peran yang dijalankan komite sekolah sebagai berikut: Memberi pertimbangan pada satuan pendidikan (sekolah) dalam penentuan dan pelaksanaan kebijakan pendidikan. Mendukung pendanaan, pemikiran, maupun tenaga dalam penyelenggaraan pendidikan di satuan pendidikan. Mengontrol agar ada transparansi dan pertanggung jawaban pendanaan pelaksanaan pendidikan di satuan pendidikan. Mediator atau penghubung antara pemerintah (eksekutif) dengan masyarakat di satuan pendidikan ${ }^{5}$.

Dalam menjalankan tugasnya, komite sekolah memiliki fungsi dan peran sebagai berikut: Menumbuhkan perhatian dan partisipasi masyarakat dalam penyelenggaraan pendidikan yang berkualitas. Menjalin kerja sama dengan masyarakat (perorangan/organisasi/dunia usaha/dunia industri) dan pemerintah setempat berkaitan dengan penyelenggaraan pendidikan yang berkualitas. Menerima gagasan masukan yang diinginkan atau dikehendaki oleh masyarakat. Memberikan masukan, pertimbangan, dan rekomendasi kepada satuan pendidikan mengenai: a. kebijakan dan program pendidikan; b. rencana anggaran pendidikan dan belanja sekolah; c. kriteria kinerja satuan pendidikan; d. kriteria tenaga kependidikan; e. kriteria fasilitas pendidikan dan hal-hal lain yang terkait dengan pendidikan. Mendorong orang tua wali siswa dan masyarakat berpartisipasi dalam pendidikan guna mendukung peningkatan kualitas dan pemetaan pendidikan. Menggalang dana masyarakat dalam rangka pembiayaan penyelenggaraan pendidikan di satuan pendidikan. Melakukan evaluasi dan pengawasan terhadap kebijakan, program, penyelenggaraan, dan keluaran pendidikan di satuan pendidikan ${ }^{6}$.

Peran komite sekolah dalam mendukung pendanaan kegiatan dan berbagai program yang tidak masuk pada anggaran dari BOS (Bantuan Operasional Sekolah), seperti membayar honor pendidik dan tenaga kependidikan tidak tetap, honor kegiatan-kegiatan ekstra kurikuler dan kegiatan lainya. Pengurus komite sekolah ditetapkan berdasarkan AD/ART yang sekurang-kurangnya terdiri atas seorang ketua, sekretaris, bendahara, dan bidang-bidang yang telah ditentukan sesuai dengan kebutuhan. Pengurus komite madrasah/sekolah dipilih dari dan oleh anggota secara demokratis.

Pengurus komite madrasah/sekolah adalah personal yang ditetapkan berdasarkan ketentuan sebagai berikut: Pengurus komite dipilih oleh anggota secara demokratis dan terbuka dalam musyawarah komite. Masa kerja komite selama tiga tahun, sebagaimana dalam permendikbud, dan anggota komite bisa berasal dari pakar pendidikan. Jika diperlukan pengurus komite sekolah dapat

\footnotetext{
${ }^{5}$ Mulyasa, 2003; Menjadi Kepala Sekolah Profesional, Bandung : ROSDA Hlm. 189

${ }^{6}$ Mulyasa, 2003; Menjadi ...hlm. 190
} 


\section{PARTISIPASI MASYARAKAT DAN MUTU PENDIDIKAN}

menunjuk atau dibantu oleh tim ahli sebagai konsultan sesuai dengan bidang keahliannya ${ }^{7}$. Adapun keanggotaan komite sekolah berasal dari unsur-unsur yang ada dalam masyarakat. Anggota komite sekolah dari unsur masyarakat dapat berasal dari komponen-komponen sebagai berikut:

(a) Perwakilan orang tua/wali peserta didik berdasarkan jenjang kelas yang dipilih secara demokratis.

(b) Tokoh masyarakat.

(c) Anggota masyarakat yang mempunyai perhatian terhadap peningkatan mutu pendidikan.

(d) Dunia industri atau dunia usaha.

(e) Pakar pendidikan yang mempunyai perhatian terhadap peningkatan mutu pendidikan.

(f) Organisasi profesi tenaga kependidikan ${ }^{8}$.

Partisipasi masyarakat dalam peningkatan kualitas pendidikan akan berhasil jika ada pemahaman yang sama antar sekolah dengan orangtua tentang visi misi tujuan sekolah. Akhirnya, upaya peningkatan kualitas sekolah akan dapat tercapai manakala sistem manajemen kepala sekolah/pimpinan mampu menjalankan fungsinya sebagai perencana, pengorganisasi, pelaksana, dan penggali upaya peningkatan kualitas sekolah. Disamping itu, seorang kepala/pimpinan juga harus mampu membangun kerjasama dengan masyarakat serta mampu menyebarkan motivasi berprestasi diantara para guru, pegawai, siswa, orang tua dan masyarakat sebagai komponen sekolah.

Penelitian sebelumnya yang terkait dengan tema ini adalah: Tesis 2017, Partisipasi Komite Sekolah dalam Meningkatkan Mutu Pendidikan di MI Maarif NU Pliken Kecamatan Kembaran Kabupaten Banyumas. Jurnal Pendidikan Islam Universitas Jambi, oleh K.A. Rahman, volume 1 no. 2 Desember 2012, Peningkatan mutu madrasah melalui penguatan partisipasi masyarakat.

\section{Kerangka Teori}

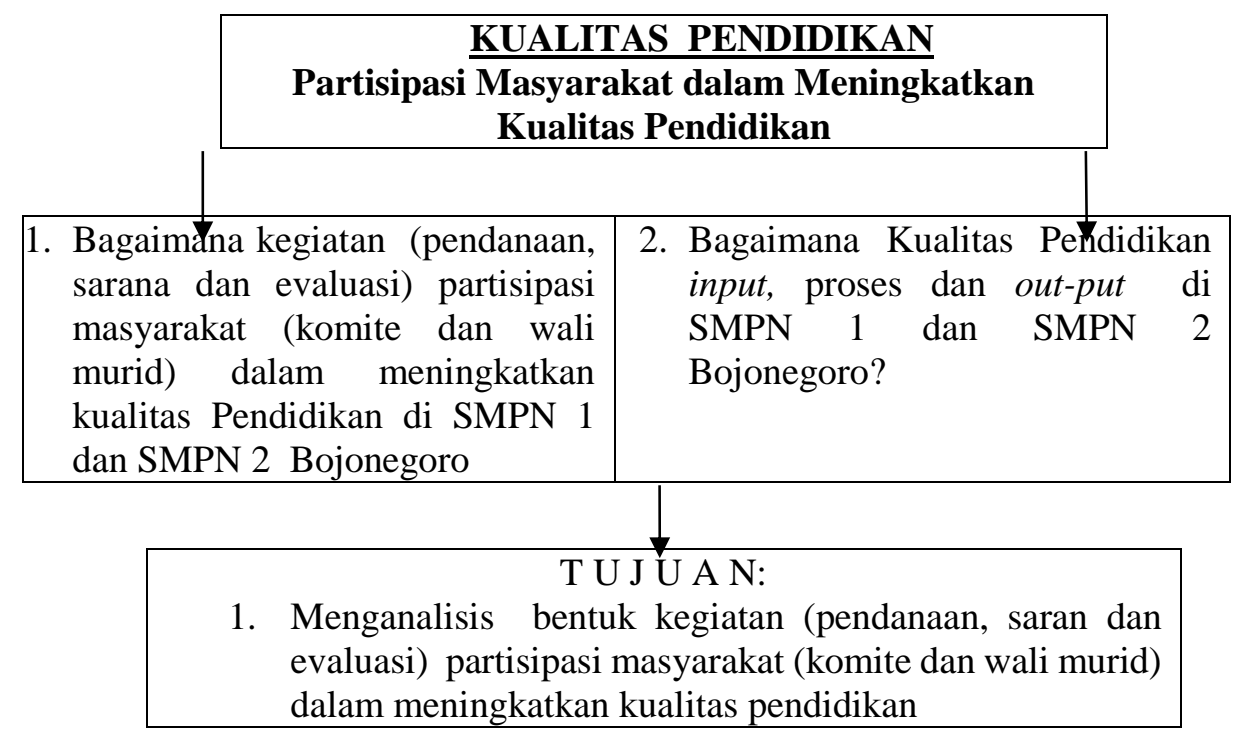

\footnotetext{
${ }^{7}$ Depdiknas, 2002 Manajemen Peningkatan Mutu Berbasis Sekolah, buku I, Jakarta, Direktorat Jendral Pendidikan Dasar dan Menengah, Hlm. 25.

${ }^{8}$ Permendikbud No. 75 Tahun 2016 Tentang Komite Sekolah
} 


\section{Sri Minarti}

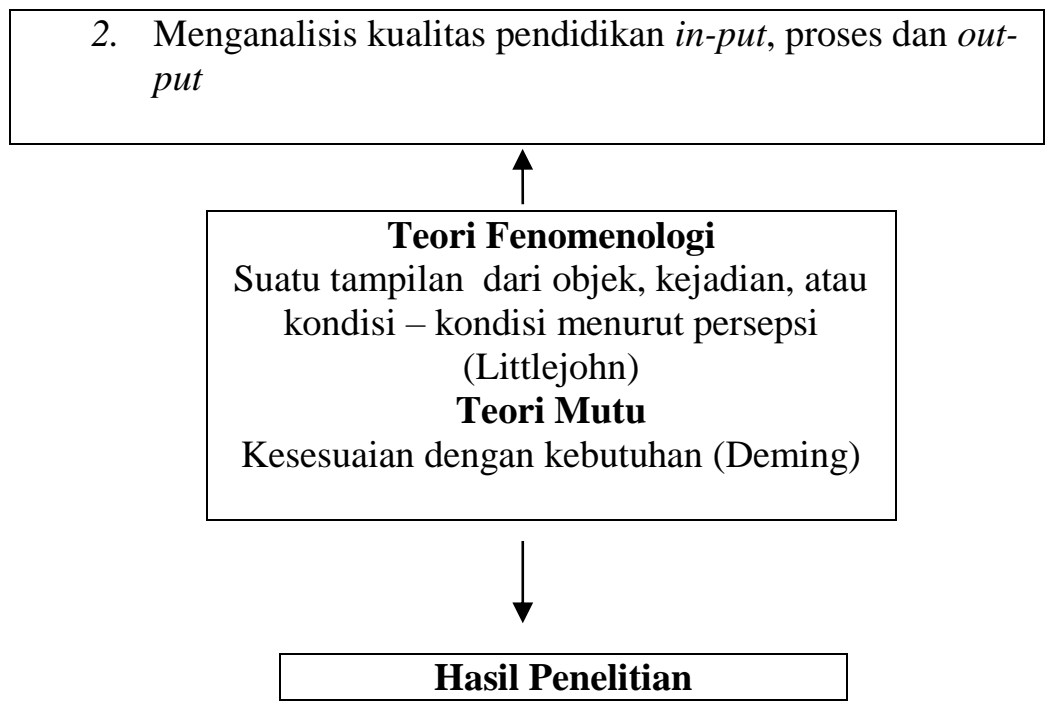

\section{Metode Penelitian}

Penelitian tentang partisipasi masyarakat dalam meningkatkan kualitas pendidikan di SMPN 1 dan SMPN 2 Bojonegoro merupakan suatu penelitian yang berusaha untuk memahami fenomena bersifat rasional, interpretatif, dan evaluatif. Pemberian makna dan interpretasi terhadap partisipasi masyarakat dalam bingkai komite dan paguyuban atau wali murid SMPN 1 dan SMPN 2 Bojonegoro bentuk kegiatan dalam bidang pendanaan, dan masukan/saran serta evaluasi guna meningkatkan kualitas pendidikan (input, proses dan out-put). Oleh sebab itu, pendekatan penelitian ini bersifat kualitatif. Pendekatan kualitatif merupakan suatu metode untuk menggali dan memahami makna atau fenomena yang oleh individu atau kelompok orang dianggap berasal dari masalah sosial. Pendekatan penelitian kualitatif yang sesuai dengan ini adalah fenomenologi. Penelitian dalam pandangan fenomenologi memiliki makna untuk memahami peristiwa kaitannya dengan orang lain dalam situasi tertentu; ${ }^{9}$ atau suatu bentuk penelitian yang menafsirkan dan menjelaskan tindakan dan pemikiran manusia, dengan cara menggambarkan struktur-struktur dasar, dan realita tampak nyata di mata setiap orang yang berpegang teguh pada sikap alamiah. ${ }^{10}$

Lokasi penelitian di SMPN 2 Bojonegoro, subjek penelitian pada wali murid, komite, dan guru serta kepala SMPN 2 Bojonegoro. Dipilihnya subjek penelitian terebut dengan pertimbangan pertama: banyak kegiatan komite dan wali murid yang sangat menunjang kualitas pendidikan di SMPN 1 dan SMPN 2 Bojonegoro sudah dipercaya oleh masyarakat dengan bukti banyaknya jumlah peserta didik. Instrumen kunci dalam penelitian ini adalah peneliti, sedangkan intrumen utama komite, wali murid, guru dan kepala SMPN 1 dan SMPN 2 Bojonegoro. Adapun teknik pengumpulan data dengan observasi yang akan menjawab tentang gambaran umum SMPN 1 dan SMPN 2 Bojonegoro, wewancara akan menjawab pertanyaan tentang kegiatan komite dan wali murid, dan dokumentasi akan menjawab

\footnotetext{
${ }^{9}$ Lexy J. Moleong, Metodologi Penelitian Pendidikan hlm. 14-15.

10 Schutz dan Luckman, 1974, hlm:3 dalam Norman K Denzin dan Yvonna S Lincoln, 2009; Handbook of, Qualitative Research, Jogjakarta: Pustaka Pelajar, hlm. 337
} 


\section{PARTISIPASI MASYARAKAT DAN MUTU PENDIDIKAN}

tentang bukti konkrit kualitas/prestasi SMPN 1 dan SMPN 2 Bojonegoro. Teknik analisis data yang peneliti lakukan dengan prinsip on going analysis, yaitu tidak dilakukan secara terpisah setelah seluruh proses pengumpulan data selesai, namun dilakukan berulang-ulang antara pengumpulan dan analisis data secara simultan. Peneliti melakukan verifikasi dengan para informan yang menjadi subjek penelitian dalam kajian ini $^{11}$. Jadi, analisis data dapat dipahami sebagai suatu proses mengorganisasikan dan mengurutkan data dalam pola, kategori, dan satuan uraian dasar sehingga dapat ditemukan tema, serta dapat dirumuskan proposisi seperti yang disarankan oleh data.

\section{Pembahasan}

Hasil wewancara dengan kepala sekolah, waka dan komite SMP Negeri 1 dan SMP Negeri 2 Bojonegoro, dapat diambil suatu makna bahwa orangtua atau wali murid memiliki hubungan emosional yang sangat kuat dengan pihak sekolahan dalam hal ini dengan kepala sekolah ataupun guru. Orangtua banyak memberi masukan pada sekolah terkait dengan kurikulum, kegiatan-kegiatan ekstra, dan sarana prasarana. Berbagai pendekatan dilakukan oleh manajemen sekolah agar hubungan komunikasi dan interaksi dapat berjalan lancar, saling bisa memberi dan menerima, diantaranya diadakannya pertemuan rutinan setiap bulan pada paguyuban kelas, pertemuan tiga bulanan dan satu semester. Penerapan pendidikan keluarga menambah semangat orangtua untuk hadir dalam setiap kegiatan di sekolah, baik yang diselenggarakan oleh siswa ataupun wali murid sendiri.

Di awal ajaran baru orangtua diberi pemahaman oleh kepala sekolah, bahwa tugas utama dan pertama mendidik anak adalah orangtua, sedangkan guru di sekolah sebagai pendidik kedua, menerima titipan amanah dari orangtua unruk membantu menjadikan dewasa, memiliki kepribadian yang baik, ilmu dan keterampilan dasar agar anak-anak mampu menghadapi tantangan kehidupan di jamannya nanti serta menempuh jenjang pendidikan yang lebih tinggi.

Kualitas pendidikan berdasarkan hasil observasi dokumen dan wawancara yang dilakukan oleh peneliti ke SMPN 1 dan SMPN 2 Bojonegoro, kedua sekolah tersebut memiliki keunggulan yang hampir sama, yaitu di samping delapan standar pendidikan yang ditawarkan oleh BNSP (Badan Nasional Standar Pendidikan) yaitu (1) standar isi, (2) standar kompetensi lulusan, (3) standar proses pendidikan, (4) standar sarana dan prasarana, (5) standar pengelolaan, (6) standar pembiayaan, (7) standar penilaian pendidikan dan (8) standar pendidik dan tenaga kependidikan, ditambah standar (9) kultur (budaya). Terpenuhinya sembilan standar

\footnotetext{
${ }^{11}$ Nana Syaodih Sukmadinata, 2000, Pengembangan Kurikulum: Teori dan Praktek, Bandung: PT. Remaja Rosdakarya. hlm. 9.
} 


\section{Sri Minarti}

yang ditawarkan oleh sekolah, dengan melibatkan peran serta orangtua wali murid serta lingkungan sekitar merupakan salah satu bukti bahwa dua sekolah kategori berkualitas.

Animo masyarakat untuk menyekolahkan anaknya di SMPN 1 dan SMPN 2 sangatlah tinggi, hal ini dapat terlihat jumlah pendaftar siswa baru pada tahun ajaran 2018/2019 di SMPN 1 berjumlah 546 anak, adapun yang diterima sebagai siswa sesuai kuota 320 anak. Untuk SMPN 2 jumlah pendaftarnya 500 anak, yang diterima sebagai siswa berjumlah 260 anak. Di dua sekolah tersebut menawarkan berbagai program kegiatan untuk mengembangkan potensi anak baik di bidang akademik maupun non akademik, dibidang akademik diberikan pembinaan persiapan olimpiade sains, pengembangan Bahasa Inggris, Bahasa Indonesia, Bahasa Jepang, dan Bahasa Arab. Di bidang non akademik dikembangkan olah raga fusal, bulu tangkis, seni tari, dan gamelan. Untuk memenuhi kebutuhan terlaksananya program sekolah tersebut, pembiayaan dimusyawarahkan dengan orangtua murid, bagi mereka siswa yang kurang mampu, tetap diperbolehkan mengikuti kegiatan, dengan pembiayaan ditanggung bersama, kurang lebih ada sekitar $20 \%$.

Dalam pengembangan karakter, sebagai wujud atau implementasi Kurikulum 2013 (K13), pembiasaan disiplin, membaca Al Qur'an secara bersama-sama sudah dimulai dari jam 06.30 - 07.00, setiap hari kecuali hari senin karena ada upacara bendera serta pembinaan yang dilakukan oleh kepala sekolah atau para guru pada guru dan siswa. Kebiasaan jum'at sedekah dengan memberi makanan atau minuman beserta snack pada tukang becak, orang yang ada di sekitar sekolahan tersebut, dan terkadang juga diberikan pada para jama'ah sholat jum'at.

Jadwal pembelajaran dari dinas pendidikan untuk sekolah menengah pertama di Kabupaten Bojonegoro sebenarnya dimulai jam 07.00-13.10 WIB, namun untuk SMPN 1 dan SMPN 2 membuat program pengembangan diri pada siswa sampai jam 14.30 WIB. Pendanaan program pengembangan berasal dari orangtua murid yang dikelola oleh komite sekolah.

Kualitas pendidikan di SMPN 1 dan SMPN 2 hampir seimbang, dapat terlihat mulai dari input yang hampir sama jumlah peminatnya sebagai pendaftar di sekolah tersebut, proses pembelajaran sama-sama adanya penambahan pengembangan diri, karakter keagamaannya dibangun dengan pembiasaan mengaji, bersikap sopan santun pada guru dan temannya, dan sholat dhuhur berjamaah, lulusannya rata-rata diterima di sekolah lanjutan atas yang favorit. Apa yang terjadi dan dilakukan oleh SMPN 1 dan SMPN 2 Bojonegoro terkait dengan partisipasi masyarakat dalam hal ini komite dan wali murid, sudah sejalan dengan Teori Fenomenologi yang dikemukakan oleh Littlejohn bahwa "suatu tampilan dari objek, kejadian, atau kondisi-kondisi menurut persepsi", suatu kegiatan yang menuju pada kualitas pendidikan selalu mendapat tanggapan yang baik dan partisipasi dari masyarakat atau wali murid yang 


\section{PARTISIPASI MASYARAKAT DAN MUTU PENDIDIKAN}

tinggi adalah benar adanya sebagaimana hasil observasi, dokumentasi dan wewancara yang dilakukan oleh peneliti, jadi bukan hanya tampilan luar atau sekedar persepsi tanpa bukti. Tentang kualitas sekolah sejalan dengan Teori Mutu yang dikemukakan oleh Deming yaitu "Kesesuaian dengan kebutuhan", bahwa sekolah menawarkan program dan mengimplementasikannya sesuai dengan harapan atau kebutuhan masyarakat dan bisa disebut selalu mengikuti perkembangan atau perubahan zaman.

\section{Kesimpulan}

Program kegiatan dalam mengembangkan potensi anak baik di bidang akademik maupun non akademik, di bidang akademik diberikan pembinaan persiapan olimpiade sains, pengembangan Bahasa Inggris, Bahasa Indonesia, Bahasa Jepang dan Bahasa Arab. Di bidang non akademik dikembangkan olah raga futsal, bulu tangkis, seni tari, dan gamelan. Untuk memenuhi kebutuhan terlaksananya program sekolah tersebut, pembiayaan dimusyawarahkan dengan orangtua murid, bagi mereka siswa yang kurang mampu, tetap diperbolehkan mengikuti kegiatan, dengan pembiayaan ditanggung bersama. Dalam pengembangan karakter, sebagai wujud atau implementasi Kurikulm 2013 (K13), pembiasaan disiplin, membaca Al Qur'an secara bersama-sama, dan jum'at berkah. Terkait dengan partisipasi masyarakat dalam hal ini komite dan wali murid, sudah sejalan dengan Teori Fenomenologi yang dikemukakan oleh Littlejohn bahwa "suatu tampilan dari objek, kejadian, atau kondisi-kondisi menurut persepsi”, memiliki arti bahwa suatu kegiatan yang menuju pada kualitas pendidikan selalu mendapat tanggapan baik dan partisipasi yang tinggi dari masyarakat atau wali murid adalah benar adanya dalam mendukung program kegiatan.

Kualitas pendidikan pada dua sekolah hampir seimbang, dapat terlihat mulai dari input yang hampir sama jumlah peminatnya sebagai pendaftar di sekolah tersebut, proses pembelajaran sama-sama adanya penambahan pengembangan diri di bidang karakter. Tentang kualitas dua sekolah sejalan dengan Teori Mutu yang dikemukakan oleh Deming yaitu "Kesesuaian dengan kebutuhan", bahwa sekolah menawarkan program dan mengimplementasikannya sesuai dengan harapan atau kebutuhan masyarakat dan bisa disebut selalu mengikuti perkembangan atau perubahan zaman.

\section{Referensi}




\section{Sri Minarti}

Departemen Pendidikan Nasional (2003) Undang Undang RI. No: 20 Tahun 2003. Tentang Sistim Pendidikan Nasional.

Depdiknas, 2003, Kamus Besar Bahasa Indonesia, Edisi Ketiga, Balai Pustaka, Jakarta.

Lexy J. Moleong, Metodologi Penelitian Kualitatif(edisi refisi) Penerbit: ROSDA Bandung

Mulyasa, 2003 : Menjadi Kepala Sekolah Profesional,: Penerbit ROSDA Bandung

Nana Syaodih Sukmadinata, 2000, Pengembangan Kurikulum: Teori dan Praktek, Bandung: PT. Remaja Rosdakarya.

Norman K Denzin dan Yvonna S Lincoln, 2009; Handbook of, Qualitative Research, Jogjakarta: Pustaka Pelajar

Permendikbud No. 75 Tahun 2016 tentang Komite Sekolah. 